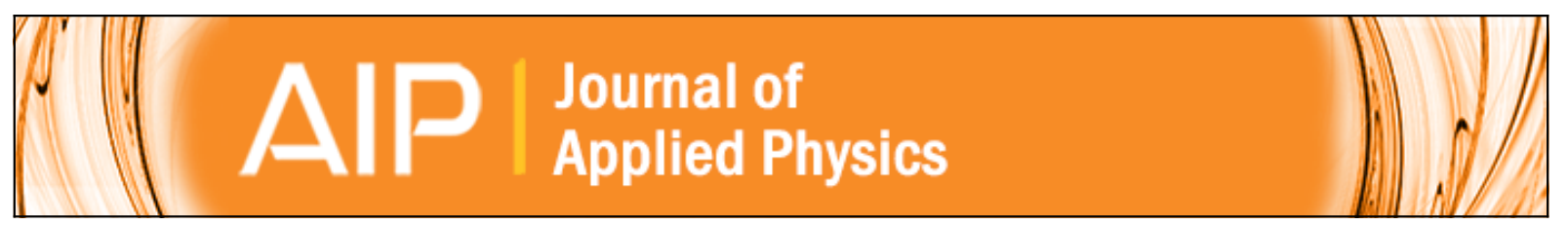

\title{
Design, fabrication, and analysis of p-channel arsenide/antimonide hetero-junction
} tunnel transistors

Bijesh Rajamohanan, Dheeraj Mohata, Yan Zhu, Mantu Hudait, Zhengping Jiang, Matthew Hollander, Gerhard Klimeck, and Suman Datta

Citation: Journal of Applied Physics 115, 044502 (2014); doi: 10.1063/1.4862042

View online: http://dx.doi.org/10.1063/1.4862042

View Table of Contents: http://scitation.aip.org/content/aip/journal/jap/115/4?ver=pdfcov

Published by the AIP Publishing

\section{Articles you may be interested in}

Ultrathin body GaSb-on-insulator p-channel metal-oxide-semiconductor field-effect transistors on Si fabricated by direct wafer bonding

Appl. Phys. Lett. 106, 073503 (2015); 10.1063/1.4906922

Operation of the GaSb p-channel metal-oxide-semiconductor field-effect transistors fabricated on (111)A surfaces

Appl. Phys. Lett. 105, 233503 (2014); 10.1063/1.4903837

Electron and hole photoemission detection for band offset determination of tunnel field-effect transistor heterojunctions

Appl. Phys. Lett. 105, 213501 (2014); 10.1063/1.4902418

Structural properties and band offset determination of p-channel mixed As/Sb type-II staggered gap tunnel fieldeffect transistor structure

Appl. Phys. Lett. 101, 112106 (2012); 10.1063/1.4752115

InxGa1-xSb channel p-metal-oxide-semiconductor field effect transistors: Effect of strain and heterostructure design

J. Appl. Phys. 110, 014503 (2011); 10.1063/1.3600220

MIT LINCOLN

LABORATORY CAREERS

Discover the satisfaction of innovation and service

to the nation
- Space Control

- Air \& Missile Defense

- Communications Systems \& Cyber Security

- Intelligence, Surveillance and

Reconnaissance Systems

\section{LINCOLN LABORATORY}

MASSACHUSETTS INSTITUTE OF TECHNOLOGY

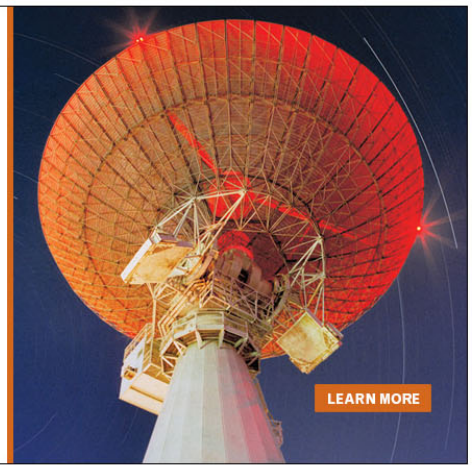




\title{
Design, fabrication, and analysis of p-channel arsenide/antimonide hetero-junction tunnel transistors
}

\author{
Bijesh Rajamohanan, ${ }^{1, a)}$ Dheeraj Mohata, ${ }^{1}$ Yan Zhu, ${ }^{2}$ Mantu Hudait, ${ }^{2}$ Zhengping Jiang, ${ }^{3}$ \\ Matthew Hollander, ${ }^{1}$ Gerhard Klimeck, ${ }^{3}$ and Suman Datta ${ }^{1}$ \\ ${ }^{1}$ Department of Electrical Engineering, The Pennsylvania State University, University Park, \\ Pennsylvania 16802, USA \\ ${ }^{2}$ Bradley Department of Electrical and Computer Engineering, Virginia Tech, Blacksburg, \\ Virginia 24061, USA \\ ${ }^{3}$ Department of Electrical and Computer Engineering, Purdue University, West Lafayette, Indiana 47906, USA
}

(Received 10 October 2013; accepted 29 December 2013; published online 23 January 2014)

\begin{abstract}
In this paper, we demonstrate InAs/GaSb hetero-junction (hetJ) and GaSb homo-junction (homJ) p-channel tunneling field effect transistors (pTFET) employing a low temperature atomic layer deposited high- $\kappa$ gate dielectric. HetJ pTFET exhibited drive current of $35 \mu \mathrm{A} / \mu \mathrm{m}$ in comparison to homJ pTFET, which exhibited drive current of $0.3 \mu \mathrm{A} / \mu \mathrm{m}$ at $\mathrm{V}_{\mathrm{DS}}=-0.5 \mathrm{~V}$ under DC biasing conditions. Additionally, with pulsing of $1 \mu$ s gate voltage, hetJ pTFET exhibited enhanced drive current of $85 \mu \mathrm{A} / \mu \mathrm{m}$ at $\mathrm{V}_{\mathrm{DS}}=-0.5 \mathrm{~V}$, which is the highest reported in the category of III-V pTFET. Detailed device characterization was performed through analysis of the capacitance-voltage characteristics, pulsed current-voltage characteristics, and x-ray diffraction studies. (C) 2014 AIP Publishing LLC. [http://dx.doi.org/10.1063/1.4862042]
\end{abstract}

\section{INTRODUCTION}

The switching slope in a metal oxide semiconductor field effect transistor (MOSFET) is limited to $60 \mathrm{mV} /$ decade at room temperature. As a result, threshold voltage scaling in a MOSFET will lead to an exponential increase in off-state leakage current $\left(\mathrm{I}_{\mathrm{OFF}}\right)$, thus limiting supply voltage scaling. ${ }^{1,2}$ Tunneling field effect transistors (TFETs) based on band-toband generation of carriers can achieve sub- $60 \mathrm{mV} /$ decade switching slope at room temperature, ${ }^{1,2}$ which would allow reduction of the supply voltage and thus the overall power dissipation in the circuit. However, the on-state current $\left(\mathrm{I}_{\mathrm{ON}}\right)$ of a TFET device needs to be enhanced in order to outperform MOSFET at low supply voltages. ${ }^{3,4}$ III-V semiconductor based TFETs have gained wide interest due to the wide range of available compositionally tunable effective barrier heights $\left(E b_{\text {eff }}\right) .^{5}$ Further, direct band-gap of these materials and lower effective mass of tunneling carriers increase the tunneling efficiency, thereby enhancing the device performance. Furthermore, these hetero-structures can be grown on either $\mathrm{GaSb}$ or InP substrates metamorphically using solid source molecular beam epitaxy (MBE) with in-situ source doping, thus realizing abrupt source-channel junctions, another important factor determining the performance of TFETs. ${ }^{6}$ III-V semiconductors based n-channel TFETs (nTFET) have already been demonstrated with sub- $60 \mathrm{mV} /$ decade subthreshold slope $(\mathrm{SS})^{7}$ and with high $\mathrm{I}_{\mathrm{ON}} \cdot{ }^{8,9}$ However, realization of TFETs in complimentary logic application requires a p-channel TFET (pTFET) with symmetrical performance. There are several challenges that need to be overcome prior to the demonstration of a high performance pTFET within the III-V semiconductor based material system. The first challenge is the integration of a high quality high-k dielectric on the $\mathrm{GaAs}_{1-\mathrm{y}} \mathrm{Sb}_{\mathrm{y}}$ channel

${ }^{\text {a)} E l e c t r o n i c ~ m a i l: ~ b o r 5067 @ p s u . e d u ~}$
(Figure 1). Antimony (Sb) dangling bonds introduce defect states near the valence band edge in GaSb. ${ }^{10}$ In fact, it was recently been demonstrated that for $\mathrm{HfO}_{2} / \mathrm{GaSb}$ interfaces, gallium (Ga) dangling bonds and $\mathrm{Sb}-\mathrm{Sb}$ antibonding states are located inside the GaSb conduction band, which is in contrast to the well-studied high- $\kappa / \mathrm{GaAs}$ in which Fermi level pinning is attributed to presence of $\mathrm{Ga}$ dangling bonds and As-As dimers. ${ }^{11,12}$ Furthermore, higher interfacial oxide content is found to be beneficial in reducing the gap states. ${ }^{12} \mathrm{~A}$ second challenge arises from the density of states (DOS) mismatch between the conduction band and the valence band. In $\mathrm{n}^{+}$ heavily doped source region of p-channel III-V TFETs, the Fermi level is degenerate and located far away from the conduction band edge, thereby preventing efficient energy filtering of conduction band holes as they tunnel from conduction band states into the valence band states in the channel. This results in a fundamental tradeoff between $\mathrm{I}_{\mathrm{ON}}$ and the switching slope in p-channel TFETs. ${ }^{13,14}$

In this work, InAs-GaSb hetero-junction (hetJ) pTFET is experimentally demonstrated using a low temperature atomic layer deposited (ALD) high- $\kappa$ dielectric. For comparison, a GaSb homo-junction (homJ) pTFET is also fabricated in this study. The device design details are discussed in Sec. II. The experimental details are covered in Sec. III. Capacitance-voltage characteristics of metal oxide semiconductor capacitors (MOSCAPs) fabricated on GaSb are systematically analyzed in Sec. IV. In Sec. V, the electrical and material characteristics of the pTFET are discussed. Sec. VI benchmarks the performance of pTFET demonstrated in this work with the reported III-V pTFETs. Sec. VII summarizes the key results from this work.

\section{DEVICE DESIGN}

Atomistic simulations ${ }^{15}$ were performed using the nonequilibrium green function method on ultra-thin body double 


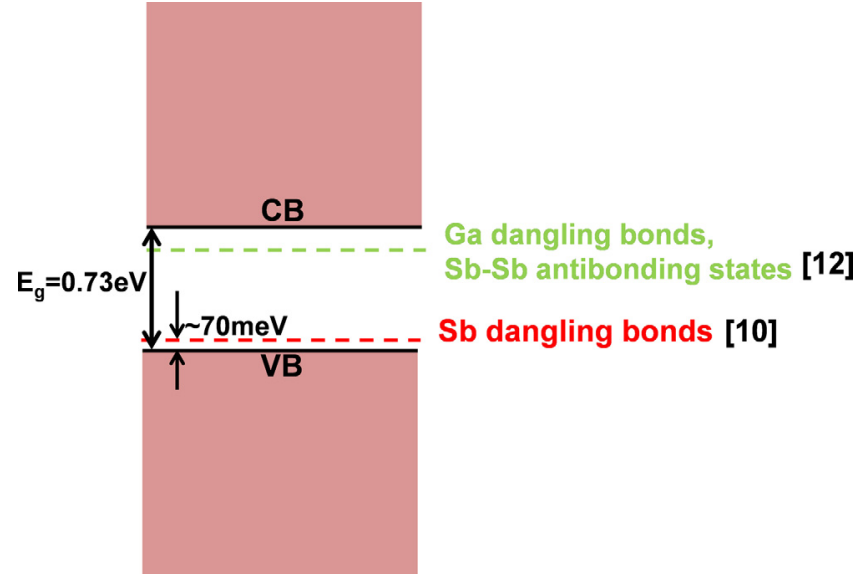

FIG. 1. Schematic illustration of the high- $\kappa / \mathrm{GaSb}$ interface states.

gate TFET structure with body thickness $\left(\mathrm{T}_{\text {body }}\right)$ of $7 \mathrm{~nm}$, equivalent oxide thickness (EOT) of $1 \mathrm{~nm}$, and gate length ( $\mathrm{L}_{\text {gate }}$ ) of $32 \mathrm{~nm}$ (Figure 2(a)). Figure 2(b) shows the transfer characteristics $\left(\mathrm{I}_{\mathrm{DS}}-\mathrm{V}_{\mathrm{GS}}\right)$ of $\mathrm{In}_{0.7} \mathrm{Ga}_{0.3} \mathrm{As} / \mathrm{GaAs}_{0.35} \mathrm{Sb}_{0.65}$ and InAs/GaSb TFETs for varying values of source doping $\left(\mathrm{N}_{\mathrm{S}}\right)$. The gate metal work-functions were adjusted so that $\mathrm{I}_{\mathrm{OFF}}$ is matched to $5 \mathrm{nA} / \mu \mathrm{m}$ in all the simulations. InAs/GaSb TFET exhibits superior characteristics compared to $\mathrm{In}_{0.7} \mathrm{Ga}_{0.3} \mathrm{As} / \mathrm{GaAs}_{0.35} \mathrm{Sb}_{0.65}$ due to smaller $\mathrm{Eb}_{\mathrm{eff}}$. InAs/GaSb nTFET with $\mathrm{N}_{\mathrm{S}}=8 \times 10^{19} \mathrm{~cm}^{-3}$ exhibits high $\mathrm{I}_{\mathrm{ON}}$ of 320 $\mu \mathrm{A} / \mu \mathrm{m} \quad$ at $\quad \mathrm{V}_{\mathrm{GS}}=0.5 \mathrm{~V}, \quad \mathrm{~V}_{\mathrm{DS}}=0.3 \mathrm{~V} \quad$ and exhibits sub- $60 \mathrm{mV} /$ decade $\mathrm{SS}$. InAs/GaSb pTFET, on the other hand, shows degraded SS for higher $\mathrm{N}_{\mathrm{S}}$ due to the low DOS of the conduction band in InAs as discussed in Sec. I. Figure 2(c) shows $\mathrm{I}_{\mathrm{ON}}$ of InAs/GaSb pTFET as a function of $\mathrm{N}_{\mathrm{S}}$ for different $\mathrm{V}_{\mathrm{GS}}$. At $\mathrm{V}_{\mathrm{GS}}=0.5$ and $0.4 \mathrm{~V}$, in order for InAs/GaSb pTFET to deliver half the $\mathrm{I}_{\mathrm{ON}}$ of $\mathrm{InAs} / \mathrm{GaSb}$ nTFET, $\mathrm{N}_{\mathrm{S}}$ of $5 \times 10^{18} \mathrm{~cm}^{-3}$ is desired. However, at $\mathrm{V}_{\mathrm{GS}}=0.3 \mathrm{~V}$, higher $\mathrm{N}_{\mathrm{S}}$ of $1 \times 10^{19} \mathrm{~cm}^{-3}$ results in lower $\mathrm{I}_{\mathrm{ON}}$. This is due to the degraded SS of the pTFET. Hence, depending on the operating voltage, $\mathrm{N}_{\mathrm{S}}$ needs to be optimized, such that the pTFET delivers enough $\mathrm{I}_{\mathrm{ON}}$ to complement the performance of nTFET. In this work, $\mathrm{N}_{\mathrm{S}}$ of $1 \times 10^{19} \mathrm{~cm}^{-3}$ is adopted for InAs/GaSb hetJ as well as GaSb homJ pTFET.

\section{EXPERIMENTAL PROCEDURES}

Figs. 3(a) and 3(b) show the schematic layer structures of InAs-GaSb hetJ pTFET and GaSb homJ, respectively, which were grown on GaSb substrates using MBE. AlSb/AlAs super-lattice was used as lattice matched isolation buffer for each structure. The pTFET fabrication starts with sputtering $300 \mathrm{~nm}$ of Molybdenum on the MBE grown samples. For the GaSb homJ sample, $60 \mathrm{~nm}$ of Titanium was evaporated prior to Molybdenum sputtering in order to facilitate the self-aligned gate deposition as explained later in this section. Titanium/Chromium hard mask was created on top of Molybdenum after patterning using electron beam lithography. Using Titanium/Chromium as etch mask, Molybdenum (Molybdenum+Titanium in case of homJ sample) and the semiconductor region comprising of source, channel, drain were etched to form a vertical pillar-like structure. In the case of hetJ sample, citric acid based solution was used to selectively wet etch InAs with respect to Molybdenum and create undercut required to form a selfaligned gate. ${ }^{16}$ Selective wet etching of GaSb with respect to Molybdenum is difficult. Hence, in the case of GaSb homJ sample, Titanium was selectively wet etched using dilute HF acid solution $\left(\mathrm{HF}: \mathrm{H}_{2} \mathrm{O}=1: 100\right)$ to create the required undercut. The pTFET samples were then treated in concentrated $\mathrm{HCl}$ solution $\left(\mathrm{HCl}: \mathrm{H}_{2} \mathrm{O}=1: 1\right)$ for 5 min followed by rinse in isopropyl alcohol (IPA). A bi-layer gate oxide comprising of $1 \mathrm{~nm} \mathrm{Al}_{2} \mathrm{O}_{3}$ and $3.5 \mathrm{~nm} \mathrm{HfO}_{2}$ was immediately deposited using ALD. Gate metal (Palladium) was vertically evaporated after patterning to form a self-aligned gate. Drain contact was then defined, oxide removed using dry-etch and
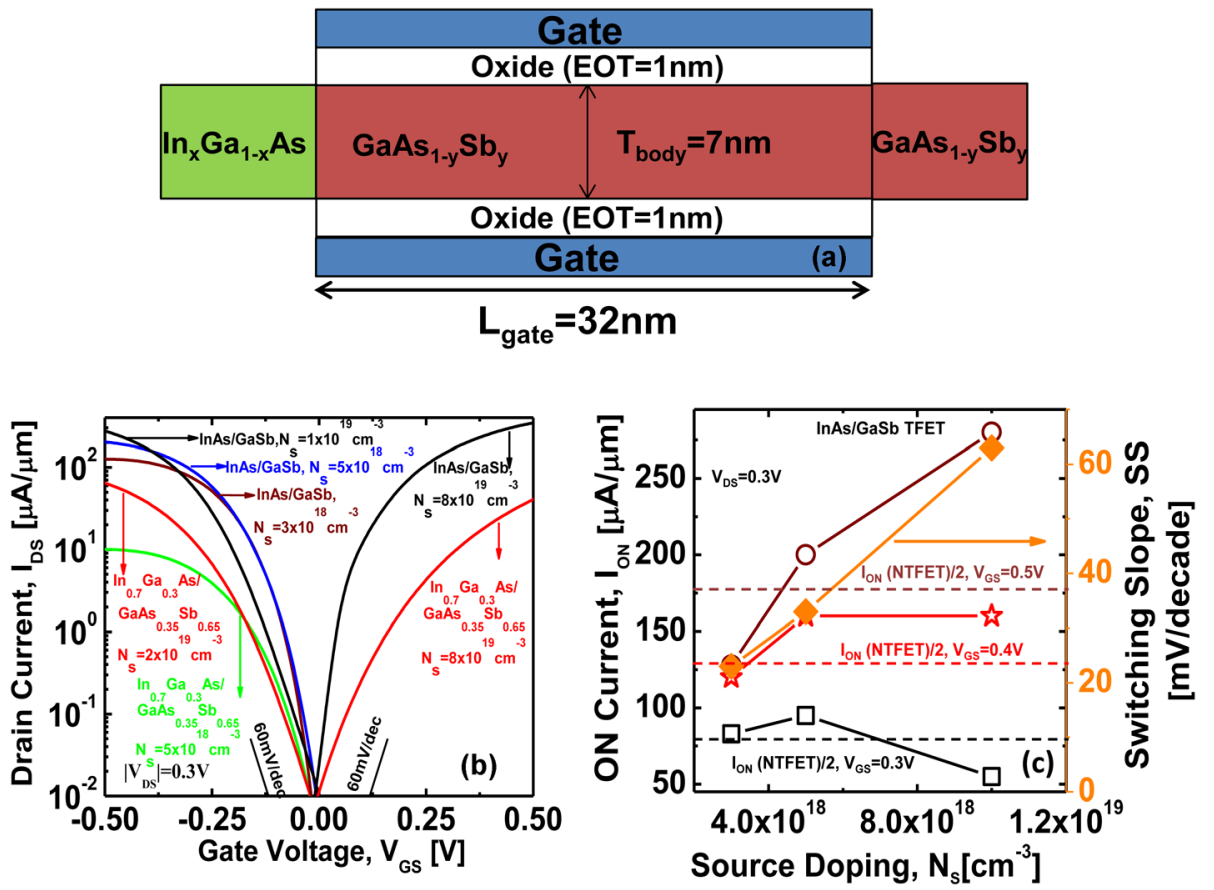

FIG. 2. (a) Schematic of ultra-thin body pTFET simulated. (b) Transfer characteristics of $\mathrm{InAs} / \mathrm{GaSb}$ and $\mathrm{In}_{0.7} \mathrm{Ga}_{0.3} \mathrm{As} / \mathrm{GaAs}_{0.35} \mathrm{Sb}_{0.65}$ pTFET as a function of the source doping. (c) $\mathrm{I}_{\mathrm{ON}}$ as a function of $\mathrm{N}_{\mathrm{S}}$ in InAs/GaSb pTFET. 

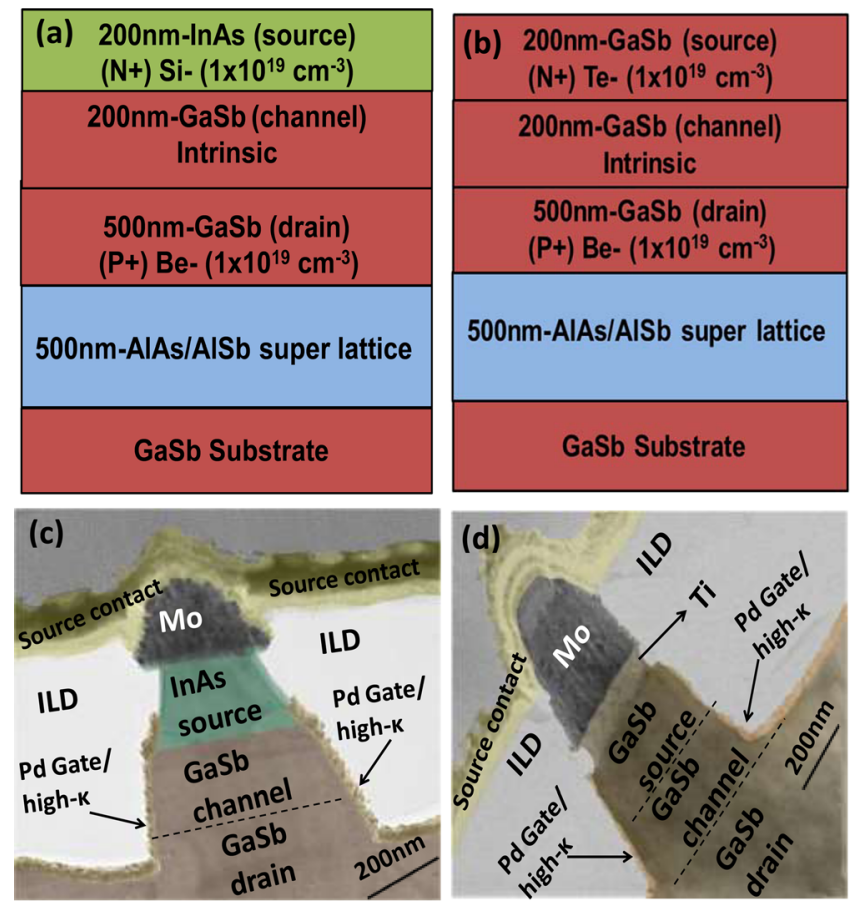

FIG. 3. (a) Schematic of MBE grown InAs-GaSb hetJ layer structure (b) Schematic of MBE grown GaSb homJ layer structure. (c) False colored cross section TEM of the fabricated InAs-GaSb hetJ. (d) False colored cross section TEM of the fabricated GaSb homJ pTFET.

$\mathrm{Ti} / \mathrm{Pd} / \mathrm{Au}$ metal stack evaporated. The samples were then baked in an inter-layer dielectric (ILD) for $60 \mathrm{~min}$ and then etched back in Oxygen plasma until the top of Molybdenum was exposed. Source contact was then defined and Titanium/Palladium/Gold metal stack evaporated. Finally, ILD was etched off from the active regions of the device. Figs. 3(c) and 3(d) show the false colored cross-section transmission electron micrograph (TEM) images of the fabricated hetJ and homJ pTFETs. For MOSCAP fabrication, samples were degreased in acetone and methanol for $5 \mathrm{~min}$ each and rinsed in IPA, followed by a dip in concentrated $\mathrm{HCl}$ solution $\left(\mathrm{HCl}: \mathrm{H}_{2} \mathrm{O}=1: 1\right)$ for $5 \mathrm{~min}$ and an IPA rinse. The samples were immediately loaded into the ALD chamber and gate oxide comprising of $1 \mathrm{~nm}$ of $\mathrm{Al}_{2} \mathrm{O}_{3}$ and $3.5 \mathrm{~nm}$ $\mathrm{HfO}_{2}$ was deposited. Following patterning the gate pad using electron-beam lithography, Palladium/Gold metal stack was evaporated to form gate contact on the MOSCAP samples. The current voltage characteristics of the pTFETs were measured using an HP parameter analyzer. Capacitance-voltage $(\mathrm{C}-\mathrm{V})$ and conductance-voltage $(\mathrm{G}-\mathrm{V})$ measurements were obtained using a HP 4285 A precision LCR meter type. Keithley 4200 Semiconductor Characterization System with a dual channel 4225 Pulse Measure Unit (PMU) was used for pulsed- $\mathrm{I}_{\mathrm{DS}}-\mathrm{V}_{\mathrm{GS}}$ measurements. X-ray reciprocal space maps (RSMs) were obtained using Panalytical X'pert Pro system with $\mathrm{Cu} \mathrm{K} \alpha-1$ as an $\mathrm{X}$-ray source. Both the symmetric (004) and asymmetric (115) RSMs were recorded from the hetJ pTFET structure.

\section{OPTIMISATION AND CHARACTERISATION OF HIGH- $\kappa / G a S b$ INTERFACE}

A low temperature ALD has been shown to improve the high- $\kappa / \mathrm{GaAs}_{0.35} \mathrm{Sb}_{0.65}$ interface resulting in improved Fermi level movement efficiency. ${ }^{17}$ The improvement in the high- $\kappa / \mathrm{GaAs}_{0.35} \mathrm{Sb}_{0.65}$ stems from the presence of Sb-oxide at low ALD temperature $\left(110^{\circ} \mathrm{C}\right) .{ }^{17}$ We have adopted a similar approach in the optimization of the high- $\kappa / \mathrm{GaSb}$ interface. Figure 4(a) shows the $\mathrm{C}-\mathrm{V}$ characteristics of ALD deposited on undoped $\mathrm{GaSb}$ at deposition temperatures $\left(\mathrm{T}_{\text {dep }}\right)$ of $110^{\circ} \mathrm{C}, 150^{\circ} \mathrm{C}$, and $200^{\circ} \mathrm{C}$, measured at $\mathrm{T}=300 \mathrm{~K}$. As $\mathrm{T}_{\text {dep }}$ is reduced, $\mathrm{C}-\mathrm{V}$ characteristics show improved modulation. Hence, ALD deposition temperature of $110^{\circ} \mathrm{C}$ was used for pTFET fabrication. The high frequency capacitance density in accumulation is close to $1.1 \mu \mathrm{F} / \mathrm{cm}^{2}$ which corresponds to an EOT of $3.4 \mathrm{~nm}$. Figure 4(b) shows the $\mathrm{C}-\mathrm{V}$ characteristics of ALD deposited at $110^{\circ} \mathrm{C}$ measured at $\mathrm{T}=300 \mathrm{~K}$ and $150 \mathrm{~K}$. At $\mathrm{T}=150 \mathrm{~K}$, reduced frequency dispersion and enhanced modulation is seen in the $\mathrm{C}-\mathrm{V}$ characteristics attributed to suppression of trap response at lower temperature. The equivalent-circuit modeling technique was used to model the measured $\mathrm{C}-\mathrm{V}$ and $\mathrm{G}-\mathrm{V}$ characteristics and extract $\mathrm{D}_{\mathrm{it}}$ and trap response time. In this approach, $\mathrm{C}-\mathrm{V}$ and $\mathrm{G}-\mathrm{V}$ characteristics are simulated as a function of frequency for various interface state density $\left(D_{i t}\right)$ and trap response time values until the error between measured and modeled values are minimized. ${ }^{18,19}$ This method is advantageous when the traps extend into the oxide and, thus, mask the conductance peaks. Traps extending $1 \mathrm{~nm}$ into the oxide were taken into consideration for modeling. ${ }^{19}$ The distribution of traps as a function of distance ' $x$ ' away from the high- $\kappa / \mathrm{GaSb}$ interface is given by
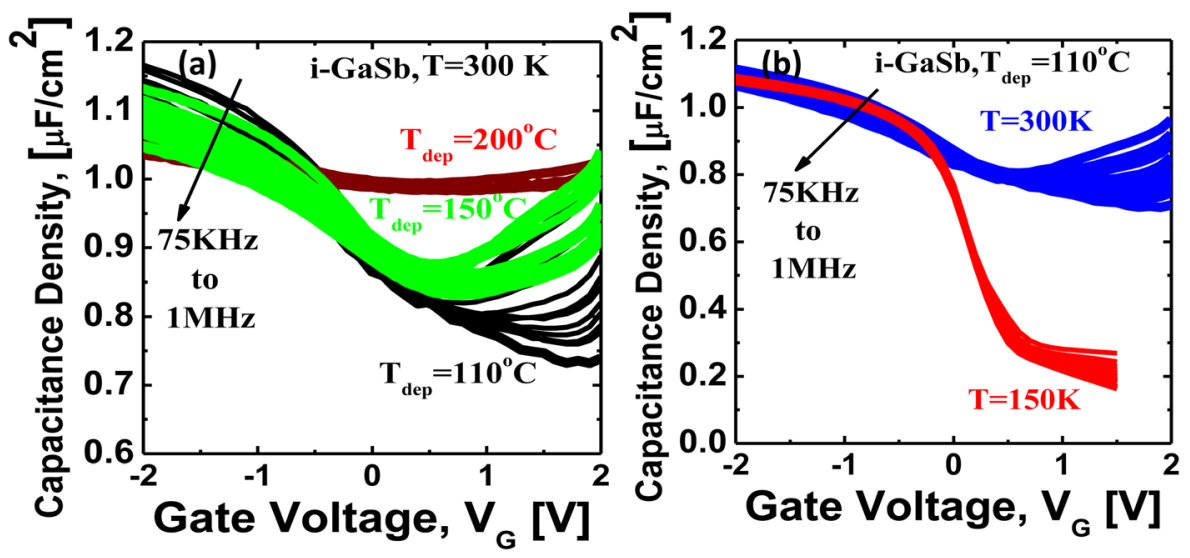

FIG. 4. (a) $\mathrm{C}-\mathrm{V}$ characteristics of $\mathrm{Al}_{2} \mathrm{O}_{3} / \mathrm{HfO}_{2}$ deposited on p-type GaSb in the frequency range of $75 \mathrm{KHz}$ to $1 \mathrm{MHz}$ measured at $300 \mathrm{~K}$ as a function of deposition temperature. (b) $\mathrm{C}-\mathrm{V}$ characteristics of $\mathrm{Al}_{2} \mathrm{O}_{3} / \mathrm{HfO}_{2}$ deposited $110^{\circ} \mathrm{C}$ and measured at $\mathrm{T}=300 \mathrm{~K}$ and $\mathrm{T}=150 \mathrm{~K}$. 


$$
N_{i t}=N_{i t}(0) \exp \left(\frac{-x}{x_{D I G S}}\right)
$$

where $\mathrm{N}_{\mathrm{it}}(0)$ is the trap density at high- $\kappa / \mathrm{GaSb}$ interface, $\mathrm{x}_{\text {DIGS }}$ is the characteristic decay length which is used as a fitting parameter $\left(x_{D I G S}=1 \AA\right)$ in the equivalent circuit model. The response time of the traps in the oxide increases exponentially as follows:

$$
\tau=\tau_{0}\left(\mathrm{E}_{\mathrm{t}}\right) \exp (2 k x),
$$

where $\tau_{0}\left(E_{t}\right)$ is the trap response time at $\mathrm{x}=0$ and at a given energy level $E_{t}$, and $k$ is the wave vector for holes tunneling from the valence band in GaSb to the traps given by

$$
k=\sqrt{2 m^{*} \Delta E_{V} / \hbar^{2}},
$$

where $\mathrm{m}^{*}$ is the hole effective mass, and $\Delta \mathrm{E}_{\mathrm{V}}$ is the valence band offset between high- $\kappa$ and GaSb.

Using $\Delta \mathrm{E}_{\mathrm{V}}=3.4 \mathrm{eV}$ (Ref. 20) and $\mathrm{m}^{*}=0.044 \mathrm{eV}$ (Ref. 21), $\mathrm{k}$ is calculated to be $0.2 / \AA$. Figures 5(a) and 5(b) show the measured and modeled $\mathrm{C}-\mathrm{V}, \mathrm{G}-\mathrm{V}$ characteristics which are in good agreement with each other. Figure 5(c) shows the extracted $D_{i t}$ as a function of gate voltage and integrated over various depths into the oxide. As more traps extending into the oxide are taken into account, the net integrated $\mathrm{D}_{\mathrm{it}}$ measured increases. Traps beyond $\mathrm{x}=0.4 \mathrm{~nm}$ do not contribute to the net integrated trap density since $x_{D I G S}=1 \AA$ and due to exponential decaying nature of the interface traps with increasing distance into the oxide, as discussed above. Figure 5(d) shows the extracted trap response time as a function of gate voltage for various trap depths into the oxide. The response time for traps increase exponentially as the distance from the interface increases. However, it should be noted that the factor $k$ is assumed to be independent of gate voltage. This might introduce some error in the calculation of trap time constants as a function of trap position in the oxide. Nevertheless, within the limits of the model used, the trap response time expected for this high- $\kappa$ gate stack on $\mathrm{GaSb}$ should be faster than $1 \mu \mathrm{s}$, since traps beyond $\mathrm{x}=0.4 \mathrm{~nm}$ do not contribute to the overall $\mathrm{D}_{\text {it }}$. Figure $5(\mathrm{e})$ shows $\mathrm{D}_{\text {it }}$ as a function of energy location in the bandgap (Eg) of $\mathrm{GaSb}$ for $\mathrm{T}_{\text {dep }}$ of $110^{\circ} \mathrm{C}$ and $200^{\circ} \mathrm{C}$. With $\mathrm{T}_{\mathrm{dep}}=200^{\circ} \mathrm{C}$, the Fermi level is pinned near the valence band edge possibly due to thermal decomposition of $\mathrm{Sb}$-oxide leading to formation of $\mathrm{Sb}$ dangling bonds which
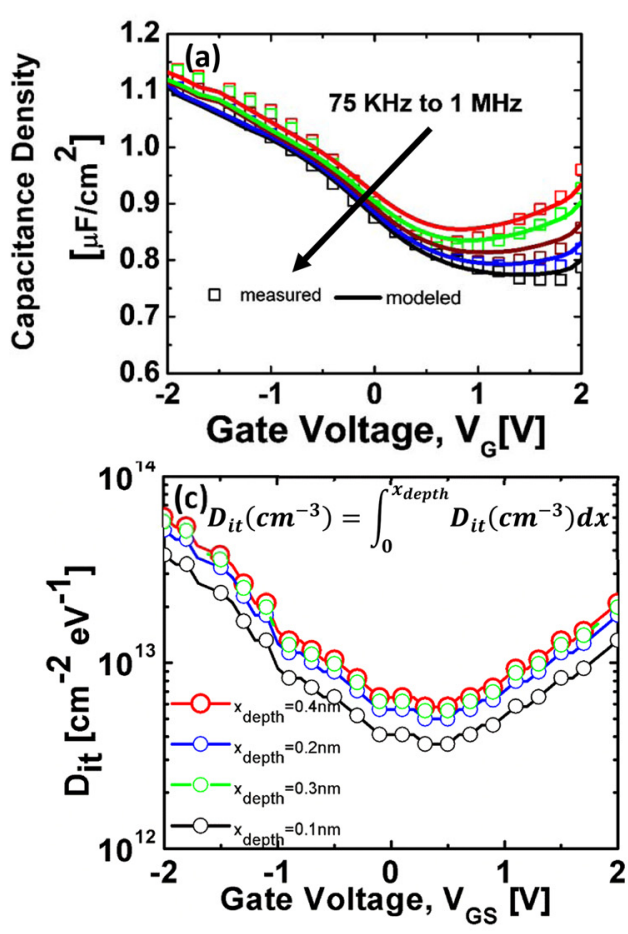
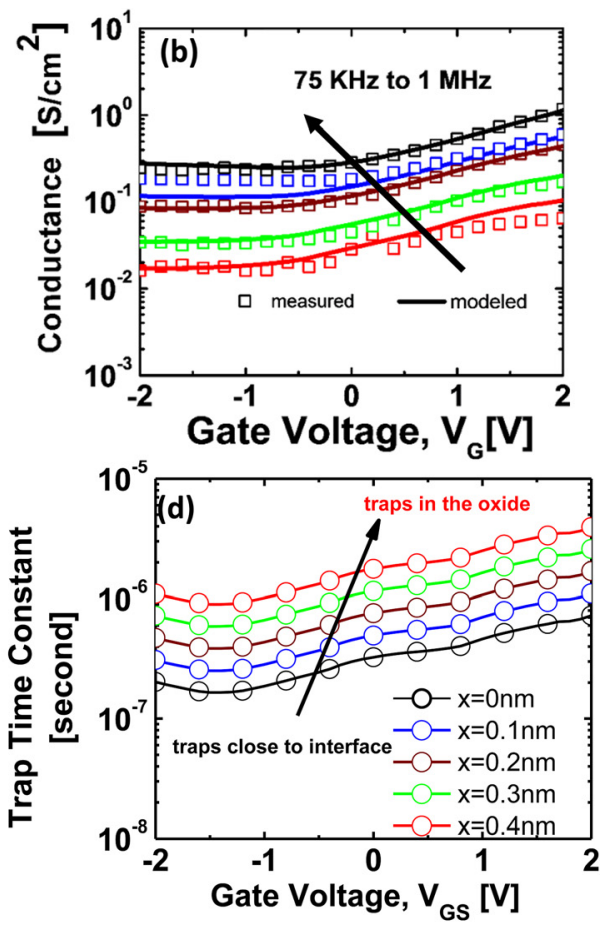

FIG. 5. (a) Measured and modeled CV characteristics at $\mathrm{T}=300 \mathrm{~K}$ as a function of frequency. (b) Measured and modeled GV characteristics at $\mathrm{T}=300 \mathrm{~K}$ as a function of frequency. (c) Extracted $D_{i t}$ as a function of gate voltage taking into account traps distributed into the oxide. (d) Extracted trap response time as a function of gate voltage taking into account traps distributed into the oxide. (e) $\mathrm{D}_{\mathrm{it}}$ as a function of energy location in the bandgap for $\mathrm{T}_{\text {dep }}=110^{\circ} \mathrm{C}$ and $200^{\circ} \mathrm{C}$.

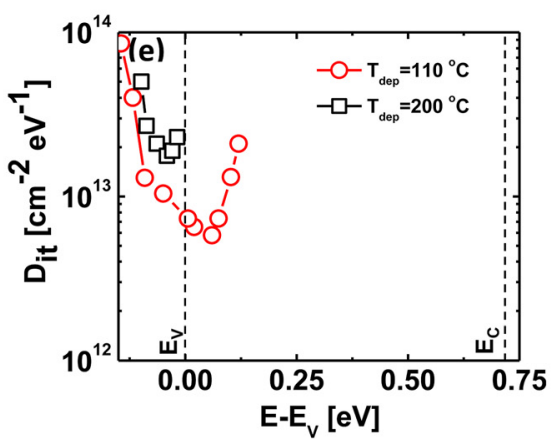


introduces high $\mathrm{D}_{\mathrm{it}}$ near valence band (Figure 2). With $\mathrm{T}_{\text {dep }}=110^{\circ} \mathrm{C}$, lower density of Sb dangling bonds could be expected due to the presence of Sb-oxide, ${ }^{17}$ and thus, the Fermi level movement improves to roughly $0.125 \mathrm{eV}$ away from the valence band edge.

\section{ELECTRICAL AND MATERIAL CHARACTERISATION OF pTFET}

Figures 6(a) and 6(b) show the $\mathrm{I}_{\mathrm{DS}}-\mathrm{V}_{\mathrm{GS}}$ characteristics of InAs/GaSb hetJ and GaSb homJ pTFETs, respectively, at $\mathrm{T}=300 \mathrm{~K}, 150 \mathrm{~K}$ and for $\mathrm{V}_{\mathrm{DS}}=-0.05 \mathrm{~V}$ and $-0.5 \mathrm{~V}$. HetJ pTFET exhibits $\mathrm{I}_{\mathrm{ON}}$ of $35 \mu \mathrm{A} / \mu \mathrm{m}$ at $\mathrm{V}_{\mathrm{DS}}=0.5 \mathrm{~V}$ at $\mathrm{T}=300 \mathrm{~K}$. GaSb homJ pTFET in comparison exhibits $\mathrm{I}_{\mathrm{ON}}$ of $0.3 \mu \mathrm{A} / \mu \mathrm{m}$ at $\mathrm{V}_{\mathrm{DS}}=0.5 \mathrm{~V}$ and $\mathrm{T}=300 \mathrm{~K}$. The difference in $\mathrm{I}_{\mathrm{ON}}$ is attributed to change in $\mathrm{Eb}_{\mathrm{eff}}$ from $0.73 \mathrm{eV}$ in $\mathrm{GaSb}$ homJ to $-0.15 \mathrm{eV}$ in hetJ pTFET. $^{22}$ Reduction in $\mathrm{I}_{\mathrm{ON}}$ at $\mathrm{T}=150 \mathrm{~K}$ is attributed to increase in band-gap with decreasing temperature and thereby, increasing the barrier for tunneling from the conduction band in the source to valence band in the channel. $\mathrm{I}_{\mathrm{OFF}}$ in hetJ pTFET is $1 \mu \mathrm{A} / \mu \mathrm{m}$, which is much higher than $\mathrm{I}_{\mathrm{OFF}}=3 \mathrm{nA} / \mu \mathrm{m}$ in GaSb homJ pTFET. High $\mathrm{I}_{\mathrm{OFF}}$ in hetero-junction material system compared to a homo-junction material system has been reported in nTFETs and attributed to defects at the hetero-interface. ${ }^{9}$ It is possible that the hetJ pTFET suffers from high defect density at the hetero-interface leading to high $\mathrm{I}_{\mathrm{OFF}}$. $\mathrm{I}_{\mathrm{OFF}}$ in hetJ pTFET was found to scale with the device cross-section area (product of width and body thickness), which confirms that $\mathrm{I}_{\mathrm{OFF}}$ is caused by bulk conduction (not shown). At $\mathrm{T}=150 \mathrm{~K}, \mathrm{I}_{\mathrm{OFF}}$ reduces substantially and $\mathrm{I}_{\mathrm{ON}} / \mathrm{I}_{\mathrm{OFF}}$ improves to $\sim 10^{4}$ in both hetJ, as well as homJ pTFET. The reduction in $\mathrm{I}_{\mathrm{OFF}}$ could be attributed to: (1) Reduction in the Shockley-Read-Hall generation-recombination current, which is a strong function
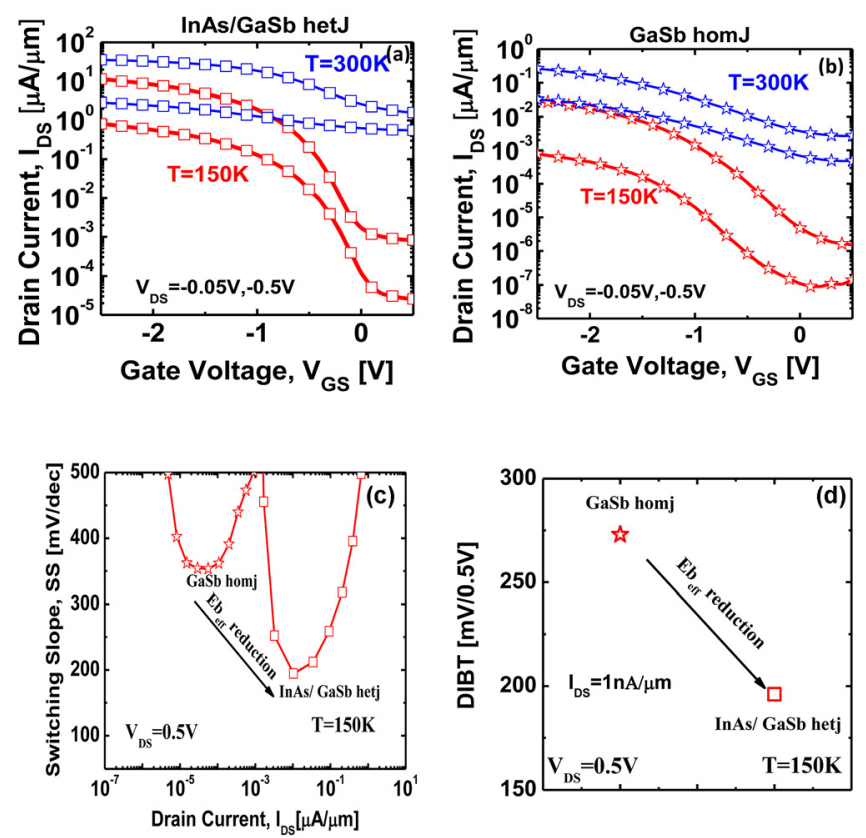

FIG. 6. (a) and (b) $\mathrm{I}_{\mathrm{DS}}-\mathrm{V}_{\mathrm{GS}}$ characteristics of hetJ and homJ pTFETs at $\mathrm{T}=300 \mathrm{~K}$ and $150 \mathrm{~K}$. (c) SS as a function of drain current at $\mathrm{T}=150 \mathrm{~K}$ showing lower SS in hetJ compared to homJ pTFET. (d) hetJ pTFET exhibits lower DIBT compared to homJ pTFET at $\mathrm{I}_{\mathrm{DS}}=1 \mathrm{nA} / \mu \mathrm{m}, \mathrm{T}=150 \mathrm{~K}$. of temperature ${ }^{23}$ and (2) suppression of $\mathrm{D}_{\text {it }}$ response, which improves the Fermi-level movement efficiency (Figure 3(b)). Figure 6(c) shows the SS as a function of drain current for both homj and hetJ pTFETs. HetJ pTFET not only exhibits lower SS but the minimum SS is observed at higher drain current. Further, hetJ pTFET shows lower drain induced barrier thinning (DIBT) in comparison to homj pTFET measured at $\mathrm{I}_{\mathrm{DS}}=1 \mathrm{nA} / \mu \mathrm{m}$ and $\mathrm{T}=150 \mathrm{~K}$ (Figure 6(d)). Lower $\mathrm{SS}$ and DIBT in hetJ pTFET stems from the reduced $\mathrm{E}_{\text {beff }}$ compared to homJ pTFET which results in interband-generation occurring closer to the source/channel interface and resulting in improved electrostatics. ${ }^{24}$ Figure 7(a) shows the $I_{D S}-V_{G S}$ characteristics of hetJ pTFET at $\mathrm{V}_{\mathrm{DS}}=0.5 \mathrm{~V}$ for varying gate voltage pulse widths. With a gate voltage pulse width of $1 \mu \mathrm{s}, \mathrm{I}_{\mathrm{ON}}$ increases to $85 \mu \mathrm{A} / \mu \mathrm{m}$ which corresponds to more than $2 \times$ improvement over $\mathrm{I}_{\mathrm{ON}}$ measured under DC bias conditions. Interestingly, with a gate voltage pulse width of $10 \mu \mathrm{s}, \mathrm{I}_{\mathrm{ON}}$ increases to $70 \mu \mathrm{A} / \mu \mathrm{m}$ which is roughly $2 \times$ of the $\mathrm{I}_{\mathrm{ON}}$ under DC bias conditions. Figure 7(b) shows the SS of hetJ pTFET as function of drain current for varying gate pulse widths. With $1 \mu$ s gate pulsing, a minimum SS of $500 \mathrm{mV} /$ decade is achieved compared to $\sim 1000 \mathrm{mV} /$ decade under DC biasing conditions. Further, with $10 \mu$ s gate pulsing, a minimum SS of $\sim 600 \mathrm{mV} /$ decade is achieved. As discussed in Sec. III, the trap response time for high- $\kappa$ on GaSb was calculated to be faster than $1 \mu \mathrm{s}$. However, since the model used for $\mathrm{C}-\mathrm{V}$ and $\mathrm{G}-\mathrm{V}$ modeling has certain limitations discussed in Sec. III, for additional confirmation, $10 \mu$ s gate pulsing was carried out and $\mathrm{I}_{\mathrm{DS}}-\mathrm{V}_{\mathrm{GS}}$ characteristic measured in homJ pTFET. HomJ pTFETs exhibit negligible change in $\mathrm{I}_{\mathrm{ON}}$ as well as $\mathrm{SS}$ (Figures 7(c) and 7(d)). To further understand the anomalous
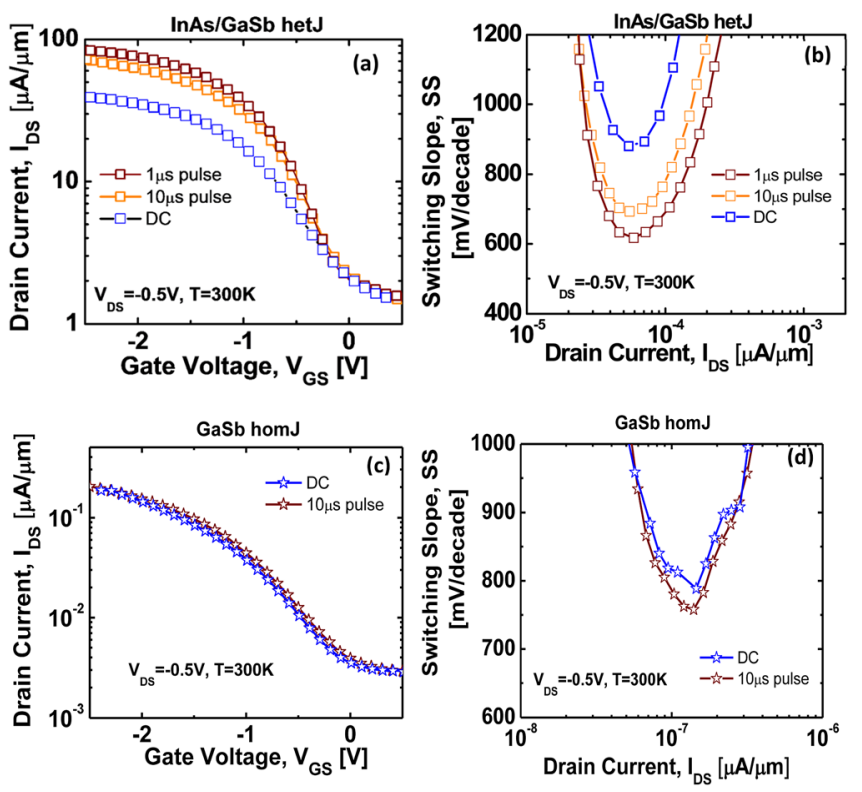

FIG. 7. (a) $\mathrm{I}_{\mathrm{DS}}-\mathrm{V}_{\mathrm{GS}}$ characteristics of hetJ for varying gate voltage pulse widths. (b) SS of hetJ pTFET as a function of drain current for varying gate voltage pulse widths. (c) $\mathrm{I}_{\mathrm{DS}}-\mathrm{V}_{\mathrm{GS}}$ characteristics of homJ pTFET show negligible change in $\mathrm{I}_{\mathrm{ON}}$ with $10 \mu$ s gate voltage pulsing compared to DC bias conditions. (d) SS of homJ pTFET shows negligible change in $\mathrm{I}_{\mathrm{ON}}$ with 10 $\mu$ s gate voltage pulsing compared to DC bias conditions. 
response to gate voltage pulsing in InAs/GaSb pTFETs, detailed material characterization was performed.

The relaxation state and residual strain of epilayers within the InAs/GaSb hetJ pTFET structure were obtained from RSMs. Figures 8(a) and 8(b) show the symmetric (004) and asymmetric (115) RSMs from this structure. All layers with measured compositions were labeled to the corresponding reciprocal lattice points (RLPs). As shown in Figures $8(\mathrm{a})$ and $8(\mathrm{~b})$, four distinct RLP maxima were found in RSMs of this structure, corresponding to (1) GaSb substrate as well as the GaSb channel/drain layers, (2) InAs source layer, (3) the satellite peaks from AlAs/AlSb super lattice, and (4) an extra $\mathrm{GaAs}_{1-y} \mathrm{Sb}_{\mathrm{y}}$ layer which is not expected from this structure. The composition of As in this layer was determined to be $\sim 2.2 \%$. As an additional confirmation, cross-section TEM of the pTFET structure was taken as shown in Figure 8(c). The presence of an amorphous layer at the hetero-junction was found, which corresponds to the $\mathrm{GaAs}_{0.022} \mathrm{Sb}_{0.978}$ layer detected in the XRD experiment. The $\mathrm{GaAs}_{0.022} \mathrm{Sb}_{0.978}$ layer may be introduced during the switching from $\mathrm{GaSb}$ channel layer to InAs source. A proper
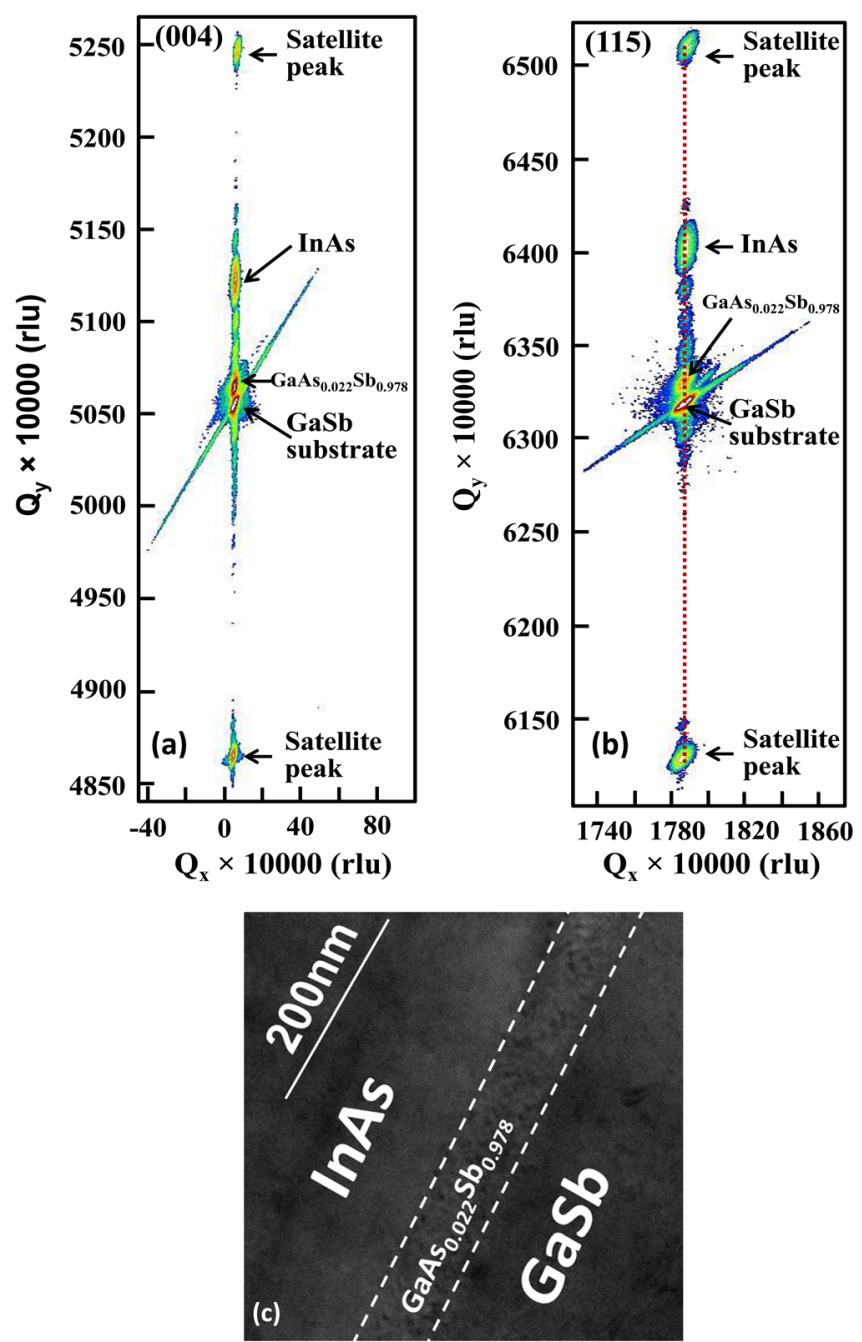

FIG. 8. (a) and (b) Symmetric and asymmetric RSM of InAs/GaSb structure showing the presence of $\mathrm{GaAs}_{0.022} \mathrm{Sb}_{0.978}$ at the hetero-junction. (c) Cross-section TEM of the InAs/GaSb structure confirming the presence of an amorphous layer of $\mathrm{GaAs}_{0.022} \mathrm{Sb}_{0.978}$ at the hetero-junction.
TABLE I. Benchmarking of $\mathrm{I}_{\mathrm{ON}}$ against experimentally demonstrated pTFET till date.

\begin{tabular}{lccccc}
\hline \hline Material & $\begin{array}{c}\mathrm{EOT} \\
(\mathrm{nm})\end{array}$ & $\begin{array}{c}\mathrm{Eb}_{\text {eff }} \\
(\mathrm{eV})\end{array}$ & $\begin{array}{c}\mathrm{V}_{\mathrm{DS}} \\
(\mathrm{V})\end{array}$ & $\begin{array}{c}\mathrm{I}_{\mathrm{ON}} \\
(\mu \mathrm{A} / \mu \mathrm{m})\end{array}$ & Reference \\
\hline $\mathrm{InAs-Si}$ & 3.65 & - & -0.5 & 0.1 & Ref. 29 \\
$\mathrm{In}_{0.7} \mathrm{Ga}_{0.3} \mathrm{As} / \mathrm{GaAs}_{0.35} \mathrm{Sb}_{0.65}$ & 3.4 & 0.25 & -0.5 & 5 & Ref. 17 \\
$\mathrm{GaSb}$ & 3.4 & 0.73 & -0.5 & 0.3 & This work \\
$\mathrm{InAs} / \mathrm{GaSb}$ & 3.4 & -0.15 & -0.5 & 85 & This work \\
\hline \hline
\end{tabular}

switching sequence of III/V elements is critical for engineering an abrupt hetero-interface during the growth of mixed $\mathrm{As} / \mathrm{Sb}$ materials, ${ }^{25-27}$ otherwise the intermixing between As and $\mathrm{Sb}$ atoms will result in uncontrolled layer composition at the hetero-interface, which will cause the change of strain relaxation properties of the epilayer grown on this interface. ${ }^{28}$ The change of strain relaxation properties may introduce high density dislocations at the hetero-interface and within the InAs source layer, which explains the high $\mathrm{I}_{\mathrm{OFF}}$ in the fabricated hetJ pTFET. Besides, the formation of $\mathrm{GaAs}_{0.022} \mathrm{Sb}_{0.978}$ layer at the hetero-interface will change the band alignment of source/channel, which leads to the increase of tunneling distance and degrade the device performance. Furthermore, the $\mathrm{GaAs}_{0.022} \mathrm{Sb}_{0.978}$ interfacial layer between InAs source and GaSb channel may also introduce unexpected interface states with the high- $\kappa$ due to the change of strain relaxation properties, and these trap states could lead to different $D_{i t}$ response for the device and might explain the anomalous pulsed $\mathrm{I}_{\mathrm{DS}}-\mathrm{V}_{\mathrm{GS}}$ response in hetJ pTFETs.

\section{BENCHMARKING}

Table I shows the performance comparison of the reported pTFETs within the III-V material system. The gate voltage is chosen sufficiently high enough to account for the stretch out in the $\mathrm{I}_{\mathrm{DS}}-\mathrm{V}_{\mathrm{GS}}$ characteristics due to the presence of $\mathrm{D}_{\mathrm{it}}$. InAs/GaSb hetJ pTFET exhibits drive current of $85 \mu \mathrm{A} / \mu \mathrm{m}$ which is the highest reported in the category of III-V pTFET. With the scaling of EOT and the reduction in $\mathrm{D}_{\mathrm{it}}$, the device characteristics are expected to improve further.

\section{CONCLUSIONS}

$\mathrm{InAs} / \mathrm{GaSb}$ hetero-junction and GaSb homo-junction pTFET were grown and fabricated using a low temperature ALD high- $\kappa$ gate dielectric. The hetJ pTFET exhibits $\mathrm{I}_{\mathrm{ON}}$ of $35 \mu \mathrm{A} / \mu \mathrm{m}$ at $\mathrm{V}_{\mathrm{DS}}=0.5 \mathrm{~V}$ under $\mathrm{DC}$ biasing conditions. Through modeling of $\mathrm{C}-\mathrm{V}$ and $\mathrm{G}-\mathrm{V}$ characteristics of MOSCAPs fabricated on GaSb substrate, $D_{i t}$ and trap response time were calculated as a functions of the extent of traps into the oxide. With $1 \mu \mathrm{s}$ gate voltage pulsing, $\mathrm{I}_{\mathrm{ON}}$ increased to $85 \mu \mathrm{A} / \mu \mathrm{m}$ at $\mathrm{V}_{\mathrm{DS}}=0.5 \mathrm{~V}$ in hetJ pTFET. Further, even with $10 \mu$ s gate voltage pulsing, $\mathrm{I}_{\mathrm{ON}}$ as well as SS improved significantly compared to the DC bias conditions. RSM study on the InAs/GaSb hetero-junction layer revealed the presence of $\mathrm{GaAs}_{0.022} \mathrm{Sb}_{0.978}$ layer at the hetero-interface which could explain the presence of slow 
interface traps in the hetJ pTFET. Improvement in the device performance can be achieved through: (a) Optimized MBE growth conditions to reduce the defects at the hetero-junction combined with reduction in body thickness which would translate to low $\mathrm{I}_{\mathrm{OFF}}$, (b) low values of $\mathrm{D}_{\mathrm{it}}$ to improve Fermi level movement efficiency and improve SS, and (c) scaled EOT to improve $\mathrm{I}_{\mathrm{ON}}$ as well as SS. In addition, density of state engineering would also be required in InAs/GaSb pTFET in order to realize TFET based complimentary logic.

\section{ACKNOWLEDGMENTS}

This work was supported in part by the NRI/SRC sponsored MIND center and by the National Science Foundation ASSIST Nanosystems ERC under award number EEC1160483. Computational resources from nanoHUB.org operated by NSF funded Network for Computational Nanotechnology under Award Number EEC-0228390 is also acknowledged. Z.J. and G.K. acknowledge support by the NEMO5 team members Prof. Michael Povolotskyi, Prof. Tillmann Kubis, and Dr. James Fonseca.

${ }^{1}$ A. M. Ionescu and H. Riel, Nature 479(7373), 329-337 (2011).

${ }^{2}$ Q. Zhang, W. Zhao, and A. Seabaugh, IEEE Electron Device Lett. 27, 297 (2006).

${ }^{3}$ M. Luisier and G. Klimeck, Tech. Dig. - Int. Electron. Devices Meet. 2009, 1.

${ }^{4}$ U. E. Avci, R. Rios, K. Kuhn, and I. A. Young, Dig. Tech. Pap. - Symp. VLSI Technol. 2011, 124.

${ }^{5}$ D. K. Mohata, R. Bijesh, T. Mayer, J. Fastenau, D. Lubyshev, A. W. K. Liu, and S. Datta, IEEE Electron Device Lett. 33, 1568 (2012).

${ }^{6}$ D. K. Mohata, R. Bijesh, Y. Zhu, M. K. Hudait, R. Southwick, Z. Chbili, D. Gundlach, J. Suehle, J. M. Fastenau, D. Loubychev, A. K. Liu, T. S. Mayer, V. Narayanan, and S. Datta, Dig. Tech. Pap. - Symp. VLSI Technol. 2012, 53-54.

${ }^{7}$ G. Dewey, B. Chu-Kung, J. Boardman, J. M. Fastenau, J. Kavalieros, R. Kotlyar, W. K. Liu, D. Lubyshev, M. Metz, N. Mukherjee, P. Oakey, R. Pillarisetty, M. Radosavljevic, H. W. Then, and R. Chau, Tech. Dig. - Int. Electron. Devices Meet. 2011, 33.6.1.

${ }^{8}$ D. K. Mohata, R. Bijesh, S. Mujumdar, C. Eaton, R. Engel-Herbert, T. Mayer, V. Narayanan, J. Fastenau, D. Loubychev, A. Liu, and S. Datta, Tech. Dig. - Int. Electron. Devices Meet. 2011, 33.5.1.
${ }^{9}$ G. Zhou, R. Li, T. Vasen, M. Qi, S. Chae, Y. Lu, Q. Zhang, H. Zhu, J.-M. Kuo, T. Kosel, M. Wistey, P. Fay, A. Seabaugh, and H. Xing, Tech. Dig. Int. Electron. Devices Meet. 2012, 32.6.1.

${ }^{10}$ L. Lin, Y. Guo, R. Gillen, and J. Robertson, J. Appl. Phys. 113, 134103 (2013).

${ }^{11}$ J. Robertson, Appl. Phys. Lett. 94, 152104 (2009).

${ }^{12}$ K. Xiong, W. Wang, D. M. Zhernokletov, K. C. Santosh, R. C. Longo, R. M. Wallace, and K. Cho, Appl. Phys. Lett. 102, 022901 (2013).

${ }^{13}$ V. Saripalli, D. K. Mohata, S. Mookerjea, S. Datta, and V. Narayanan, in 68th Annual Device Research Conference (DRC) (IEEE, DRC, 2010), p. 103.

${ }^{14}$ B. Rajamohanan, D. Mohata, A. Ali, and S. Datta, Appl. Phys. Lett. 102, 092105 (2013).

${ }^{15}$ S. Steiger, M. Povolotskyi, H.-H. Park, T. Kubis, and G. Klimeck, IEEE Trans. Nanotechnol. 10(6), 1464-1474 (2011).

${ }^{16}$ D. K. Mohata, R. Bijesh, V. Saripalli, T. Mayer, and S. Datta "Self-aligned gate nano pillar $\operatorname{In}_{0.53} \mathrm{Ga}_{0.47}$ As vertical tunnel transistor," in 69th Annual Device Research Conference (IEEE, 2011), pp. 203-204.

${ }^{17}$ B. Rajamohanan, D. Mohata, D. Zhernokletov, B. Brennan, R. M. Wallace, R. E. Herbert, and S. Datta, Appl. Phys. Express 6, 101201 (2013).

${ }^{18}$ A. Ali, H. Madan, S. Koveshnikov, S. Oktyabrsky, R. Kambhampati, T. Heeg, D. Schlom, and S. Datta, IEEE Trans. Electron Devices 57, 742 (2010).

${ }^{19}$ A. Ali, H. Madan, M. J. Barth, J. B. Boos, B. R. Bennett, and S. Datta, IEEE Electron Device Lett. 34, 360 (2013).

${ }^{20}$ I. Geppert, M. Eizenberg, A. Ali, and S. Datta, Appl. Phys. Lett. 97, 162109 (2010).

${ }^{21}$ A. K. Walton and U. K. Mishra, J. Phys. C 1, 533 (1968).

${ }^{22}$ W. Li, Q. Zhang, O. A. Kirillov, R. Bijesh, Y. Liang, D. Mohata, B. Tian, X. Liang, S. Datta, C. A. Richter, D. J. Gundlach, and N. V. Nguyen, in 71 st Annual Device Research Conference (IEEE, 2013).

${ }^{23}$ S. Mookerjea, D. Mohata, T. Mayer, V. Narayanan, and S. Datta, IEEE Electron Device Lett. 31, 564 (2010).

${ }^{24}$ D. Mohata, S. Mookerjea, A. Agrawal, Y. Y. Li, T. Mayer, V. Narayanan, A. Liu, D. Loubychev, J. Fastenau, and S. Datta, Appl. Phys. Express 4, 024105 (2011).

${ }^{25}$ K. Herbert, Physica E 20, 196 (2004).

${ }^{26}$ Y. Zhu, N. Jain, S. Vijayaraghavan, D. K. Mohata, S. Datta, D. Lubyshev, J. M. Fastenau, W. K. Liu, N. Monsegue, and M. K. Hudait, J. Appl. Phys. 112, 024306 (2012).

${ }^{27}$ J. Wang, G. W. Wang, Y. Q. Xu, J. L. Xing, W. Xiang, B. Tang, Y. Zhu, Z. W. Ren, Z. H. He, and Z. C. Niu, J. Appl. Phys. 114, 013704 (2013).

${ }^{28}$ Y. Zhu, N. Jain, S. Vijayaraghavan, D. K. Mohata, S. Datta, D. Lubyshev, J. M. Fastenau, A. K. Liu, N. Monsegue, and M. K. Hudait, J. Appl. Phys. 112, 094312 (2012).

${ }^{29}$ H. Riel, K. E. Moselund, C. Bessire, M. T. Bjork, A. Schenk, H. Ghoneim, and H. Schmid, Tech. Dig. - Int. Electron. Devices Meet. 2012, 16.6.1. 